\title{
Stability Analysis Based on Theoretical Data and Inclining Test Results for a 1200 GT Coaster Vessel
}

\author{
Siti Rahayuningsih",a,", Eko B. Djatmiko ${ }^{1, b}$, Joswan J. Soedjono ${ }^{1, c}$ and Setyo Nugroho $^{\text {2,d }}$ \\ ${ }^{1}$ Departement of Ocean Engineering, Institut Teknologi Sepuluh Nopember, Surabaya, Indonesia \\ ${ }^{2}$ Department of Marine Transportation Engineering, Institut Teknologi Sepuluh Nopember, \\ Surabaya, Indonesia \\ a. Sitirahayuningsih9@gmail.com \\ *corresponding author
}

Keywords: $\quad$ coaster vessel, final stability, preliminary stability.

Abstract: 1200 GT Coaster Vessel is designed to mobilize the flow of goods and passengers in order to implement the Indonesian Sea Toll Program. This vessel is necessary to be analysed its stability to ensure the safety while in operation. The stability is analysed, firstly by theoretical approach (preliminary stability) and secondly, based on inclining test data to derive the final stability. The preliminary stability is analysed for the estimated LWT of 741.20 tons with LCG $23.797 \mathrm{~m}$ from AP and VCG $4.88 \mathrm{~m}$ above the keel. On the other hand, the inclining test results present the LWT of 831.90 tons with LCG $26.331 \mathrm{~m}$ from AP and VCG $4.513 \mathrm{~m}$ above the keel. Stability analysis on for both data is performed by considering the standard reference of IMO Instruments Resolution A. 749 (18) Amended by MSC.75 (69) Static stability, as well as guidance from Indonesian Bureau of Classification (BKI). Results of the analysis indicate that the ship meets the stability criteria from IMO and BKI. However results of preliminary stability analysis and final stability analysis exhibit a difference in the range $0.55 \%$ to $11.36 \%$. This put forward better result from the final stability analysis due to the less accuracy in preliminary stability computation.

\section{Introduction}

Based on the form and construction, the ship has certain functions that depend on three main factors, namely the type of cargo carried, ship structure materials, and ship operating areas. The specialization of the type of payload has an impact on the enhancement of efficiency and productivity. One of the Indo $\neg$ nesian government programs in terms of sea transport is the provision of coaster vessels which are functioned as pioneer ships to serve small remote and underdeveloped islands [1].

The procurement program of pioneer vessels is one step in increasing inter-island connectivity. A total of 100 units of pioneer ship orders by the Directorate General of Sea Transportation are currently under construction by several shipyards in Indonesia. To ensure the safety and security of passengers and cargoes pioneer vessels are necessary to fulfill the stability requirements of ships based on the applicable safety standards of IMO (International Maritime Organization) and the Indonesian Bureau of Classification (BKI). 
In the study presented in this paper, stability analysis of a 1200 GT coaster vessel served as a pioneer ship has been carried out. The analysis is based on numerical model and inclining test. The analysis was conducted with seven loading conditions. Inclining test was conducted by moving the test load on the ship and then the tilting angle was measured.

\section{Basic Theory}

\subsection{Ship Stability}

A ship is a passenger and/or cargo carrying vehicle operated at all regions having certain water area [2,3]. A major challenge in designing a new ship is the presence of many parameters that must be technically met. One of them is the ship must be in a stable balance condition when operated. The correlation of the centre of gravity to the metacentre will determine the stability of a ship [4]. The centre of gravity will change if there is addition, subtraction, or moving charge on board [5]. Floating objects are otherwise balanced if the centre of gravity $(\mathrm{G})$ and the centre of buoyancy $(\mathrm{B})$ are on a line perpendicular to the water surface [2].

In general ship stability may be classified into two (2) main categories, namely [6]:

1. Static stability: applicable to stationery vessels and heeled to a certain angle determined by the magnitude of the returning or righting moment. The static stability in relation of righting moment consists of:

a) Initial stability: the evaluation performed on stability is based on the metacentric point, denoted by $\mathrm{M}$, the centre point of gravity $\mathrm{G}$ and further the distance between the centre of gravity with the metacentric point, denoted by GM. This method is applicable to a small inclination angle, where the metacentric point is assumed to be fixed.

b) Large angle stability: Evaluation is performed on a heeled ship with a large inclination angle, where the position of point $\mathrm{M}$ is not fixed, and which determines the stability of the ship is the magnitude of the righting arm GZ.

2. Dynamic stability: the stability indicated by the magnitude of the work or the addition of potential energy generated by the fluctuation of the reversal moment during the process of ship inclination to a certain angle.

\subsection{Inclining Test}

Inclining test is the practice of stability investigation after a new ship is completed [2]. The purpose of this procedure is to obtain precisely the weight and center gravity of the unloaded vessel and is a recommendation required by the classification body [7]. Once the ship is afloat, the weight and center of gravity can be determined accurately by the inclining test [8].

This test is performed to determine and check the height of the vessel's center of gravity above the keel, especially for newly completed vessels and for vessels after undergoing considerable construction changes.

When inclining test is performed, displacement and longitudinal position of the ship's center of gravity are found from observed drafts. To get $G M$, the metacentric height, is determined in the following manner by $G Z$, the righting arm at small angle of inclination $\phi$ :

$$
G Z=G M \sin \phi
$$

From which it follows that the righting moment is:

$$
W \cdot G Z=W \cdot G M \sin \phi
$$


Where, $W$ is the displacement of the ship determined from the drafts.

The heeling moment, $M$, produced by moving a weight, $w$, aboard ship perpendicular to the ship's centerline plane through a distance, $d$, hence:

$$
M=w \cdot d \cos \phi
$$

Since the righting moment and heeling moment are equal at the time the inclination is then measured by:

$$
\begin{gathered}
W \cdot G M \sin \phi=w \cdot d \cos \phi \\
G M=\frac{w \cdot d \cos \phi}{W \sin \phi} \\
G M=\frac{w \cdot d}{W \tan \phi}
\end{gathered}
$$

The height of the ship's center of gravity is found by subtracting the metacentric height $G M$ from the height of the metacentre above the keel $K M$,. When the ship so inclined has a considerable trim, it is usually necessary to calculate the displacement and $K M$ by using Bonjean curves for the actual trimmed condition. The height of the metacenter may be read from the displacement and other curves at the draft above the center of flotation, after the draft at the center of flotation has been obtained from the observed drafts.

To find the real center of gravity of the ship, the free surface effect, as well as the virtual $G M$, must be subtracted from the height of the metacenter, or:

$$
K G=K M-G M-\frac{1}{W} \sum \frac{i}{\delta}
$$

\subsection{Free Surface Effect}

Free surface effect in this case is referring to the influence of liquid-free surfaces in the tank when the tank is not fully loaded. When the tank is fully filled with liquid, the liquid will not move inside the tank when the ship is heeled. But if the tank is not full then when the ship heels the liquid surface inside the tank will gather on the side of the ship's heel. This will affect the weight of ship centre of gravity $G$ out of the center line plane, resulting in an increase in the apparent $G$ or referred to as $G$, and minimize the value of $G M$ that affects the moment of static stability.

Theoretically, the free surface effect againts the metacentric height can be assesed by assuming that the weight of the liquid in each tank works at the metacenter of the tank. This is equivalent to assuming that the weight of the liquid in each tank is raised from its centroid in the upright position to its metacenter, a distance of $i_{r} / v$. This increases the vertical moment of the mass of the ship by $(w / g)\left(i_{r} / v\right)$, where $w$ is the weight of the liquid. If the spesific volume of the liquid, expressed as volume or mass, is designed as $\delta$, then $w / g=v / \delta$ and the increase in vertical mass moment becomes:

$$
\frac{v}{g} \cdot \frac{i r}{v} \cdot=\frac{i r}{\delta}
$$

An expression which is independent of the quantity of liquid in the tank. Therefore, for any condition of loading, free surface may be evaluated for small angles of heel, by adding the values of $\mathrm{ir} / \delta$ for all tanks in which a free surface exists if this summation, which is the increase in vertical moment due to the free surface, is divided by the ship's centre of gravity caused by the free-surface effect. This rise, called the free surface correction is added to $K G$. The height of the ship's centre of 
gravity above the keel, resulting in an equivalent reduction in the metacentric height. Hence, with displacement in mass units is:

$$
G M_{\text {correction }}=K B+B M-K G-i r / \delta \Delta
$$

or with displacement in weight units,

$$
G M_{\text {correction }}=K B+B M-K G-g i r / \delta W
$$

\subsection{Standard of Safety and Stability}

In order to ensure the safety and security of ship operations at sea, international agencies such as IMO in Instruments Resolution A. 749 (18) Amended by MSC.75 (69) Static Stability [9], set minimum criteria for all ships. So in analysing the stability of the ship must refer to the standard set by the IMO and the guidance of the Indonesian Bureau of Classification (BKI) as a mandatory requirement of a ship to be allowed to sail.

Stability rules apply to different types of ships and marine structures of 24 meters or more. Different types of vessels are based on the function and configuration of each ship. The stability of a vessel will affect the type of each ship. The ship type studied herein is a 1200 GT coaster vessel. In accordance with IMO A.749 the stability criteria is specified with reference to the graph in Figure 1.

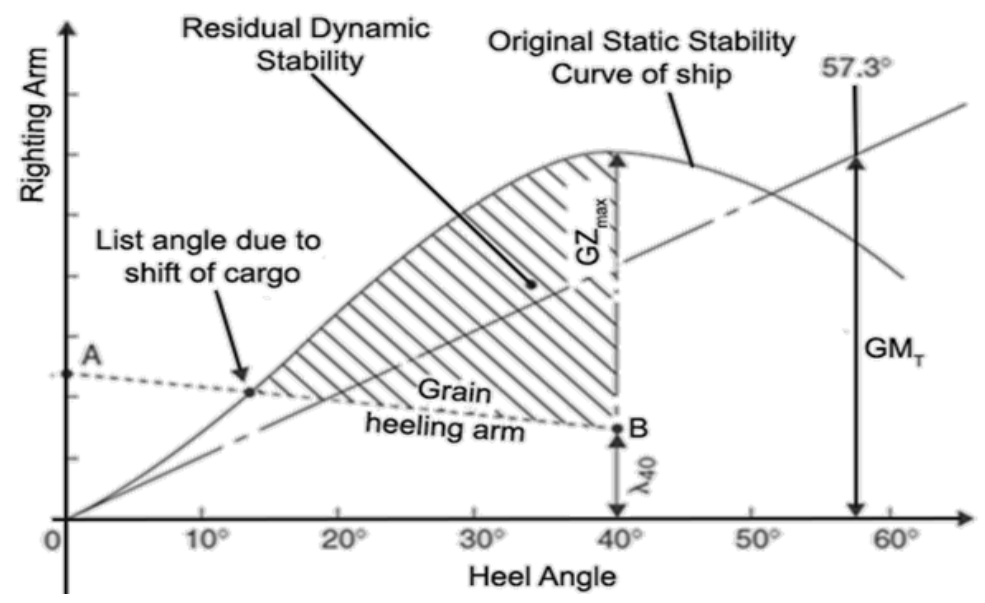

Figure 1. GZ curve for static stability criteria

IMO in Instruments Resolution A. 749 (18) Amended by MSC.75 (69) Static Stability [9] requires the following provisions:

1) Section A.749 (18) Chapter 3.1.2.1:

a) The area under the righting lever curve ( $G Z$ curve) should be not be less than 3.151 m.deg at heeling angle range $0^{\circ} \sim 30^{\circ}$;

b) The area under the righting lever curve ( $G Z$ curve) should be not be less than 5.157 m.deg at heeling angle range $0^{\circ} \sim 40^{\circ}$;

c) The area under the righting lever curve ( $G Z$ curve) between heeling angle of $30^{\circ} \sim 40^{\circ}$ should be not be less than 1.719 m.deg.

2) Section A749 (18) Chapter 3.1.2.2: the righting lever GZ should be at least $0.20 \mathrm{~m}$ at a heeling angle equal to or greater than $30^{\circ}$. 
3) Section A. 749 (18), Chapter 3.1.2.3: the maximum righting lever GZ should occur at an angle of heel preferably exceeding $25^{\circ}$ but not less than $25^{\circ}$.

4) Section A.749 (18), Chapter 3.1.2.4: the initial metacentric height $G M$ at $0^{\circ}$ angle should not be less $0.15 \mathrm{~m}$.

5) Section A.749 (18), Chapter 3.1.2.5: for passenger ships, the angle of heel on account of crowding of passengers to one side as defined in paragraphs 3.5.2.6 to 3.5.2.9 should not exceed $10^{\circ}$.

6) Section A.749 (18), Chapter 3.1.2.6: for passenger ships, the angle of heel on account of turning should not exceed $10^{\circ}$.

In addition to the above parameters, IMO also requires calculation of stability due to wind load. Wind will result in steady heel on the vessel so its stability needs to be revisited. In this case the criterion given by IMO is the steady heel angle due to wind load must be less than $16^{\circ}$. Comparison of Area- 1 to Area- 2 should be more than $100 \%$. Where Area- 1 is the extent of the $G Z$ curve under the wind heeling arm and Area-2 is the extent of the $G Z$ curve above the wind heeling arm [9].

\section{Method of the Study}

\subsubsection{Literature Study}

This stage the authors to search the source of information and references as supporting materials in this study. The source of reference and information that the authors get from various national and international journals, books, course materials, codes and various references from the internet.

Table 1. Main dimensions of the 1200 GT coaster vessel

\begin{tabular}{|l|l|l|}
\hline Description & Value & Unit \\
\hline Length Over All $(L O A)$ & 62.80 & meter \\
\hline Length between Perpendiculars $(L P P)$ & 57.36 & meter \\
\hline Breadth $(B)$ & 12.00 & meter \\
\hline Depth $(H)$ & 4.00 & meter \\
\hline Design Draught $(T)$ & 2.70 & meter \\
\hline Other data: & 12 & knot \\
\hline Speed $(V)$ & $2 \times 1000$ & HP \\
\hline Main Engine Power & 36 & pers \\
\hline Number of Crew & \multicolumn{2}{|l|}{} \\
\hline Passenger & 372 & pers \\
\hline Economy Class & 18 & pers \\
\hline $2^{\text {nd }}$ Class & 8 & pers \\
\hline $1^{\text {st }}$ Class & \multicolumn{2}{|l}{} \\
\hline
\end{tabular}




\subsubsection{Procedure of Evaluation}

At this stage, stability analysis is performed by numerical modelling and analysis based on the data of ship's slope test results.

\subsubsection{Data Collection}

Data to support the work of this study will be collected in order to facilitate and increase the accuracy of the study results. The ship data of 1200 GT coaster vessels used for this study are presented Table 1.

\section{Result and Discussions}

\subsection{Modelling the 1200 GT Coaster Vessel}

Based on the data that has been collected then ship modelling is performed in the form of 3dimension drawings using Maxsurf software. Modelling of the ship consists of images of the ship hull viewed from side view, from the front, from the top, and the three-dimensional facet. The 1200 GT coaster vessel modelling is presented in Figure 2 to 5. This vessel model is further used in the modelling and stability analysis.

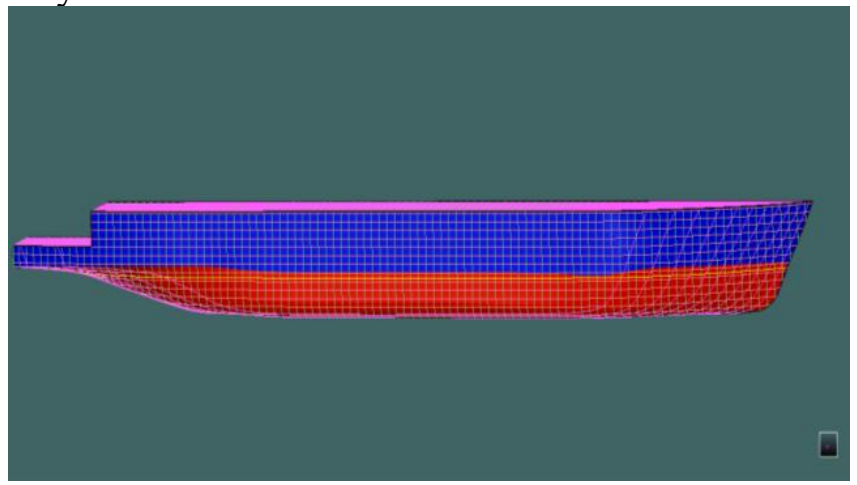

Figure 2. 3-D model of the 1200 GT Coaster Vessel

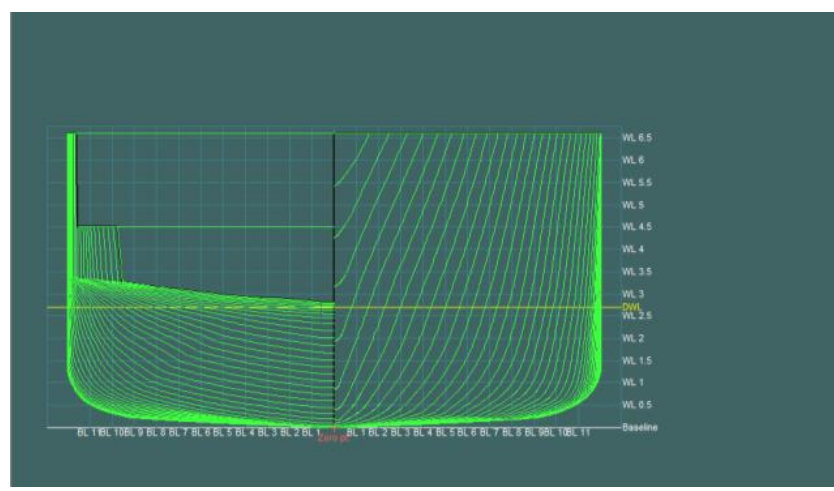

Figure 3. Body plan of the 1200 GT Coaster Vessel 


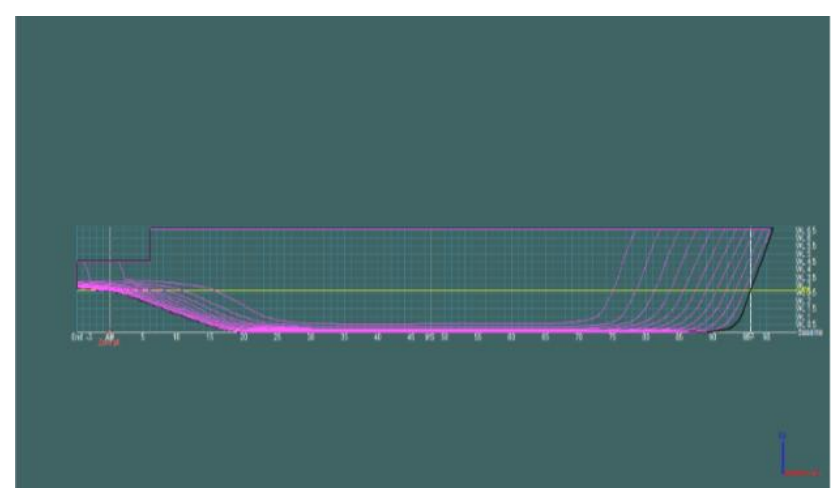

Figure 4. Sheer plan of the 1200 GT Coaster Vessel

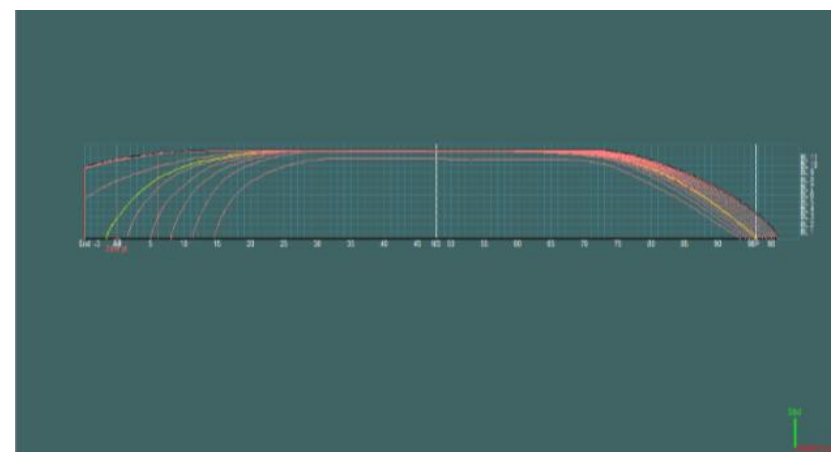

Figure 5. Half breadth plan of the 1200 GT Coaster Vessel

Table 2. Validation of hydrostatic data

\begin{tabular}{|l|l|l|l|l|l|}
\hline Item & Unit & Model & Design & Differenc & Status \\
\hline $\begin{array}{l}\text { Displacement } \\
(\Delta)\end{array}$ & ton & 1,321 & 1,318 & $0.23 \%$ & Ok \\
\hline $\begin{array}{l}\text { Voume Displacement } \\
(\nabla)\end{array}$ & $\mathrm{m}^{3}$ & $1,288.58$ & $1,285.85$ & $0.21 \%$ & Ok \\
\hline Length Water Line $(L W L)$ & $\mathrm{m}$ & 58.319 & 58.794 & $0.81 \%$ & Ok \\
\hline Wetted Area $(W S A)$ & $\mathrm{m}^{2}$ & 761.093 & 761.029 & $0.01 \%$ & Ok \\
\hline Waterplane Area $(W P A)$ & $\mathrm{m}^{2}$ & 584.275 & 583.183 & $0.19 \%$ & Ok \\
\hline Prismatic Coef. $(C p)$ & & 0.732 & 0.722 & $1.39 \%$ & Ok \\
\hline Block Coef. $(C b)$ & & 0.682 & 0.676 & $0.89 \%$ & Ok \\
\hline Waterplane Area Coef. $(C w)$ & & 0.835 & 0.827 & $0.97 \%$ & Ok \\
\hline$L C B$ & $\mathrm{~m}$ from AP & 29.359 & 29.468 & $0.37 \%$ & Ok \\
\hline$L C F$ & $\mathrm{~m}$ from AP & 27.338 & 27.688 & $1.26 \%$ & Ok \\
\hline$K B$ & $\mathrm{~m}$ & 1.49 & 1.497 & $0.47 \%$ & Ok \\
\hline$B M_{T}$ & $\mathrm{~m}$ & 4.653 & 4.66 & $2.37 \%$ & Ok \\
\hline$B M_{L}$ & $\mathrm{~m}$ & 96.548 & 96.025 & $0.54 \%$ & Ok \\
\hline$K M_{T}$ & $\mathrm{~m}$ & 6.144 & 6.263 & $1.90 \%$ & Ok \\
\hline$K M_{L}$ & $\mathrm{~m}$ & 98.038 & 97.522 & $0.53 \%$ & Ok \\
\hline
\end{tabular}

\subsection{Validation of Hydrostatic Data}

After the modeling is accomplished as in the discussion above, the subsequent process will get hydrostatic data based on the model that has been made. In order to ensure the similarity of ship models that have been made with the actual ship design, it is necessary to validate the hydrostatic 
data. Validation is done by comparing the hydrostatic data that has been obtained from the modeling with the actual ship's hydrostatic data. Validation of hydrostatic data in more detail can be seen in Table 2.

\subsection{Stability Analysis Based on Modelling Data}

After the modeling and validaation of hydrostatic data of the 1200 GT coaster vessel are completed, the next step is to perform the calculation and analysis of initial stability or prelimenary stability. In this study, a preliminary stability analysis was conducted with variations of seven different loading conditions or load cases. The seven conditions were analyzed using the assumption of LWT data obtained on the basis of calculation, i.e. 741.2 tons, with LCG of $23.797 \mathrm{~m}$ measured from AP, and KG $4.88 \mathrm{~m}$ measured from the baseline. From the preliminary stability analysis, we obtain the results of the ship righting moment data as represented by the righting arm GZ, shown in the curves of Figure 6.

Based on the data contained in the graphs of Figure 6, it can be read the initial value of GMT, and then listed in Table 3.

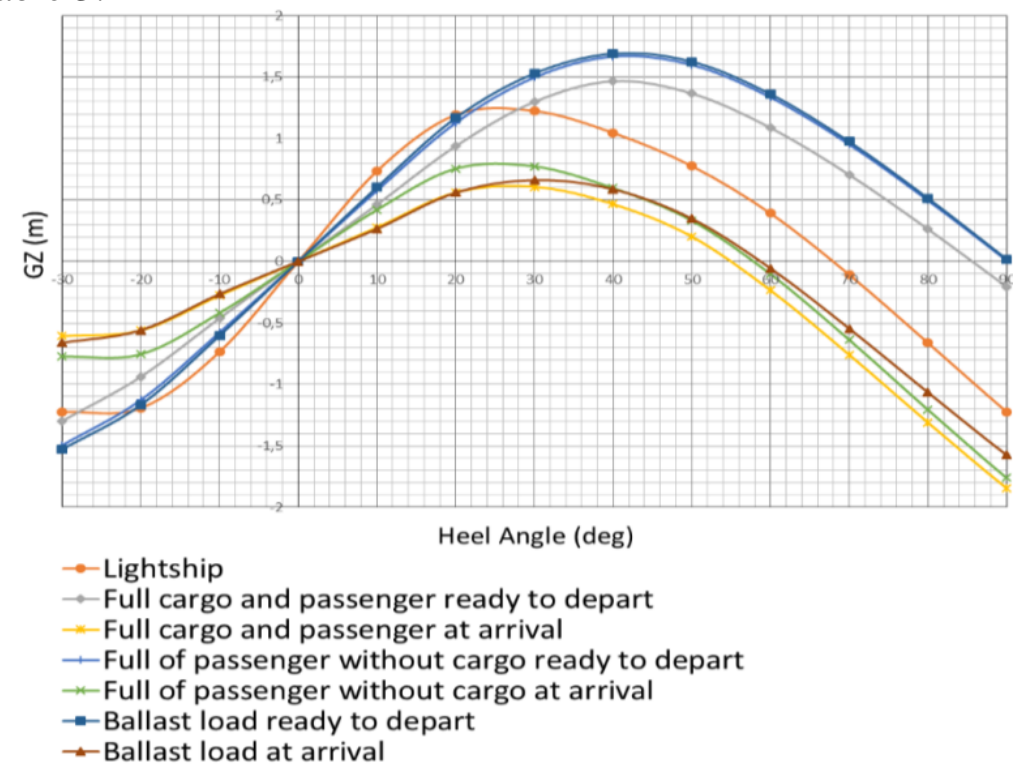

Figure 6. GZ curves for 7 variation of load cases from modeling

Table 3. Values of GMT for initial stability

\begin{tabular}{|l|l|}
\hline Loadcase & Initial $\boldsymbol{G M}_{\boldsymbol{T}}(\mathbf{m})$ \\
\hline Lightship & 4.290 \\
\hline Full cargo and passenger ready to depart & 2.563 \\
\hline Full cargo and passenger at arrival & 1.450 \\
\hline Full of passenger without cargo ready to depart & 3.353 \\
\hline Full of passenger without cargo at arrival & 2.241 \\
\hline Ballast load ready to depart & 3.509 \\
\hline Ballast load at arrival & 1.438 \\
\hline
\end{tabular}

Based on Figure 6 it can be seen that the best stability is obtained when the vessel is in the condition of ballast load ready to depart, while the lowest stability condition occurs in the full cargo and passenger at port of arrival. This is the impact of the difference of the location of center of gravity 
$G$ on the each loading condition. In the condition of ballast loading ready to depart, the load distribution on the vessel is commonly found in ship tanks where most of them are located at the bottom of the vessel. Obviously this causes the vertical position of the center of gravity of ship $G$ is relatively low.

The lower center of gravity $G$ leads to the higher the metacentric height $G M$ that causes the length of $G Z$ is also greater if the ship is heeling. Here $G Z$ acts as the arm of the ship's returning moments to its original position. This causes the stability of the vessel in the condition of the ballast load ready to depart to be higher. Conversely the vessel condition with full passengers and cargo arriving at the port of destination has a lower stability because in this condition the distribution of loads occurs at the upper part of the ship. While the load on the tanks at the bottom has been much reduced. This results in a higher $G$, so the $G M$ value is smaller and produces a shorter $G Z$ arm when the ship heels. As a result the stability of the vessel becomes lower due to of the smaller righting arm.

\subsection{Inclining Test Procedure and Data}

The 1200 GT coater vessel is registered to BKI. Therefore the building of this ship considers all rules and regulations as endorsed by BKI, including the inclining test procedures. Inclining test has been performed by shifting certain loads onboard of the vessel followed by the measurement of the heeling angle and the length of deviation [10]. Inclining test has been conducted on 29 September, 2017 at 20:30.

During the inclining test has been used four blocks of test load, as described in Table 4. The arrangement of positioning the test load on the crew deck is as shown in Figure 7.

Table 4. Weight of the test loads

\begin{tabular}{|l|l|}
\hline Identification & Weight (Tonnes) \\
\hline Block 1 & 4,003 \\
\hline Block 2 & 3,718 \\
\hline Block 3 & 3,950 \\
\hline Block 4 & 4,022 \\
\hline
\end{tabular}

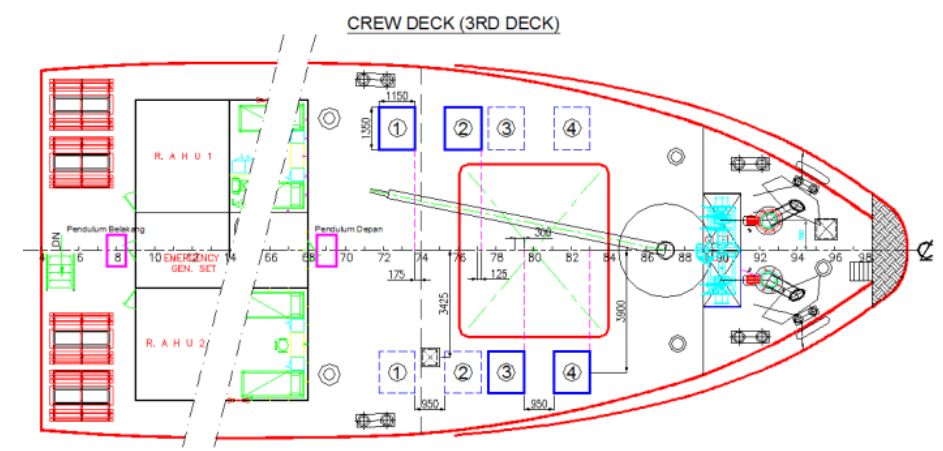

Figure 7. Positioning of the test loads on the 1200 GT coaster vessel

The inclining test gives data of light ship weight LWT in the order of 831.9 ton, LCG of 26.331 $\mathrm{m}$, and $\mathrm{KG}$ of $4.513 \mathrm{~m}$.

\subsection{Stability Analysis Based on Inclining Test Data}

After the inclining test then proceed with analysing the final stability based on the results obtained from the inclining test. The final stability analysis was performed for eight conditions, of 
which seven conditions were based on conditions such as preliminary stability and with additional halfway conditions. Results of the stability computation in this respect are exhibited in Figure 8 . The $G M_{T}$ height for the eight conditions read from Figure 8 is shown in Table 5.

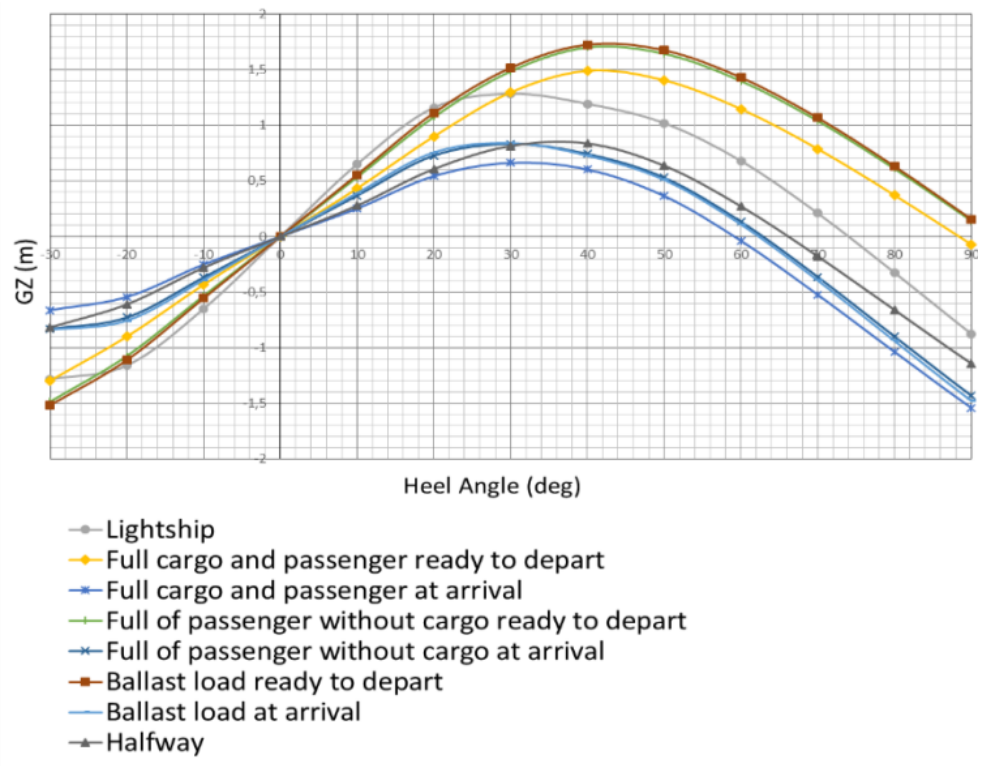

Figure 8. GZ curves for 8 variation of load cases based on inclining test data

Based on Figure 8. It can be seen that the best stability based on the inclining test data is found to be in the condition of ballast load ready to depart, while the lowest stability condition occurs in the full passenger cargo load at the port of arrive. As explained previously that this is the impact of the difference in the location of the ship's center of gravity on the condition of each variation.

Table 5. Values of GMT for final stability

\begin{tabular}{|l|l|}
\hline Loadcase & Initial $\boldsymbol{G M}_{\boldsymbol{T}}(\mathbf{m})$ \\
\hline Lightship & 3.598 \\
\hline Full cargo and passenger ready to depart & 2.352 \\
\hline Full cargo and passenger at arrival & 1.360 \\
\hline Full of passenger without cargo ready to depart & 2.993 \\
\hline Full of passenger without cargo at arrival & 1.959 \\
\hline Ballast load ready to depart & 3.116 \\
\hline Ballast load at arrival & 2.089 \\
\hline Halfway & 1.491 \\
\hline
\end{tabular}

\subsection{Comparison of Stability Based on Modelling and Inclining Test}

In the case of 1200 GT coaster vessel it is found that there are differences in results from prelimenary stability analysis based on the modelling with final stability analysis based on inclining test. In preliminary stability, the light weight of the vessel is 741.2 tons, $L C G 23.797 \mathrm{~m}$, and $K G 4.88$ $\mathrm{m}$. While in the final stability the light weight is of 831.9 tons, $L C G 26.331 \mathrm{~m}$, and $K G 4.513 \mathrm{~m}$. Where the results show that final stability is more stable in comparison to the preliminary stability prediction. This conclusion is based on the fulfillment of IMO criteria and it may be said that the 
preliminary stability analysis is less accurate due to the discrepancy in the data if compared to final stability calculations.

\section{Conclusions}

The results of the study of 1200 GT coaster vessel stability based on modeling and inclining test that has been conducted produced a number of conclusions as follows:

- Stability analysis based on the modelling indicates the best stability is found in the vessel with ballast load ready to depart, whereas the lowest stability presents when the vessel full of passenger and cargoes at arrival.

- Inclining test is conducted by shifting the test loads and then measuring the heeling angle and the length of the deviation. From the inclining test results obtained $L W T$ of 831.9 tons, $L C G$ of 26.331 $\mathrm{m}$, and of $K G 4.513 \mathrm{~m}$.

Results of the computation based on the inclining test data provides better stability values when compared to the numerical modelling results for some criteria of IMO.

\section{Suggestions}

Based on the findings of the current study, there are two points need to be pursued further in relation with the safety evaluation of the 1200 GT coaster vessel, as follows:

- It is important to conduct dynamic stability analysis and damaged stability analysis at $1200 \mathrm{GT}$ coaster vessel.

- 1200 GT coaster vessel partly is a passenger carrier, so it is necessary to do seakeeping analysis to ensure passenger comfort and ship effectiveness.

\section{Acknowledgements}

The authors would like to convey sincere gratitude to Dr. Agoes A. Masroeri, the head of National Ship Design and Engineering Center (NaSDEC) of ITS, who has provided the financial support for this paper to be presented at MASTIC 2018.

\section{References}

[1] I. Baihaqi, S.R.W. Pribadi, H. Supomo, "Production capacity analysis of national shipyard in Indonesia to build sea toll ships," Applied Mechanics and Materials, Vol. 874, pp. 174-180, Jan. 2018

[2] M. Sofi'i, Teknik Konstruksi Kapal Baja Jilid I, Direktorat Jenderal Pembinaan Sekolah Menengah Kejuruan. Direktorat Jenderal Manajemen Pendidikan Dasar dan Menengah. Departemen Pendidikan Nasional. Jakarta, 2008

[3] I.G.N.S. Buana, F. Hadi, and T. Shinoda, "Vessel selection to support coal-fired power plant supply using multi criteria analysis”, Applied Mechanics and Materials, Vol. 874, pp. 207-214, Jan. 2018

[4] L.G. Taylor, The Principle of Ship Design, Brown and Son Publiser Ltd, Glasgow, 1977

[5] J. Hind, Trim and Stability of Fishing Vessel, Fishing News Ltd. London, 120p, 1967

[6] M. Hikam, W. Wardhana, and I. Rochani, "Analisis geometri dan konfigurasi lolom-ponton terhadap intensitas gerakan dan stabilitas semisubmersible”, Jurnal Teknik ITS, vol. 1, no. 1, 2012

[7] BKI, Petunjuk Pengujian Kemiringan Periode Oleng Kapal Vol. C, Jakarta, 2003.

[8] E.V. Lewis, Principal of Naval Architecture Second Revision Volume I: Stability and Strength, The Society of Naval Architects and Marine Engineers, Jersey City, USA, 1988

[9] IMO, Intact Stability for All Type of Ships, Resolution A.749 (18) as amended by MSC.75, Stability Criteria for All Types of Ships, London, 2008 
[10] P. Stevan, T.W. Pribadi, and S.I. Wahidi, "Computer-based android application for vessel's condition survey by owner surveyor," Applied Mechanics and Materials, Vol. 874, pp. 165-173, Jan. 2018. 